\title{
The Comparison of Macroseismic Intensity Scales
}

\author{
R.M.W. Musson ${ }^{1}$, G. Grünthal ${ }^{2}$ and M. Stucchi ${ }^{3}$ \\ 1. British Geological Survey, West Mains Road, Edinburgh, EH9 3LA, UK \\ Email: rmwm@bgs.ac.uk tel: +44-131-650-0205 fax: +44-131-1677-1877 \\ 2. GFZ German Research Centre for Geosciences, Telegrafenberg, D-14473 \\ Potsdam, Germany \\ 3. INGV Milano, via Bassini 15, 20133 Milano, Italy
}

\section{Abstract}

The number of different macroseismic scales that have been used to express earthquake shaking in the course of the last 200 years is not known; it may reach three figures. The number of important scales that have been widely adopted is much smaller, perhaps about eight, not counting minor variants. Where data sets exist that are expressed in different scales, it is often necessary to establish some sort of equivalence between them, although best practice would be to reassign intensity values rather than convert them. This is particularly true because difference between workers in assigning intensity is often greater than differences between the scales themselves, particularly in cases where one scale may not be very well defined. The extent to which a scale guides the user to arrive at a correct assessment of the intensity is a measure of the quality of the scale. There are a number of reasons why one should prefer one scale to another for routine use, and some of these tend in different directions. If a scale has many tests (diagnostics) for each degree, it is more likely that the scale can be applied in any case that comes to hand; but if the diagnostics are so numerous that they include ones that do not accurately indicate any one intensity 
level, then the use of the scale will tend to produce false values. The purpose of this paper is chiefly to discuss in a general way the principles involved in the analysis of intensity scales. Conversions from different scales to the European Macroseismic Scale is discussed.

\section{Keywords}

Intensity, intensity scales, macroseismology, history of seismology 


\section{Introduction}

In the beginning was the Scale, and the name of the Scale was Rossi-Forel.

The above is actually not strictly correct, but serves as a reminder that there was a time, at the end of the $19^{\text {th }}$ century, when macroseismic intensities were assessed throughout the world using a single, recognised intensity scale. This was the Rossi-Forel Scale (de Rossi 1883), and thus "intensity" and "Rossi-Forel" (RF) were effectively synonymous, and intensity came in ten degrees, since this was the number of degrees in the RF Scale. It is rather curious that today, RF intensity is largely forgotten.

Although RF was the first scale ever to be widely adopted, it was, of course, not the first intensity scale. It was itself a compromise between the scales proposed independently and near-simultaneously by de Rossi (1874) and Forel (1881). But the first recognisable intensity scale in the modern understanding of the term goes back to the work of Egen (1828), some fifty years previously. Egen's innovation was ahead of its time.

In the course of time, the inadequacies of the RF scale led to the development of modified versions, entirely new scales, and modifications that so departed from the original that they were effectively new scales. As of 1921, Charles Davison was able to identify 27 different intensity scales, though some of these were subjective, or classifications of earthquakes rather than strength of shaking at a place (Davison 1921). A follow-up study in 1933 increased the number of different scales from 27 to 39, with between three and twelve degrees (Davison 1933). Obviously the number has considerably increased since then.

From the reader's point of view, the multiplicity of scales can be confusing and cause problems of interpretation. This is all the more the case when (as is very frequent) the scale used in any study is not distinctly identified. The comparison of different intensity scales is thus an important issue, which has not really been 
studied in any depth in the literature. Under the general heading of "comparison", two separate issues can be identified. The first is the vexed practical question of conversion between scales. If one wishes to establish a correlation between (say) epicentral intensity and magnitude, and one has a table of values from one study of RF intensities, and another of MSK (Medvedev-Sponheuer-Karník) intensities, can they be combined, and if so, how? The second is a more theoretical question of the evaluation of scales. Can one say that one scale is better than another? Both these issues will be addressed in this paper.

It should be understood that intensity scales have more than one use in seismology. The original purpose of using intensity was to parameterise earthquake effects in a descriptive way, from observational data. More recently, intensity has also been used in a predictive way, in hazard and risk studies, where loss estimates can be inferred from expected intensity values. The present paper is concerned chiefly with the observational use of intensity scales (as, for instance, by institutes responsible for seismic monitoring, including web-based macroseismic surveys, or in studies of historical earthquakes). It should also be stressed that this paper intends to discuss the general issues involved in comparing and evaluating intensity scales; it is not intended to be a review of any particular scales in themselves.

\section{Cancani and non-Cancani scales}

However, there is a particular matter that requires some preliminary discussion, and that is the number of degrees a scale may have, and in particular, the division of intensity scales into two classes: firstly, those that have twelve degrees and descend ultimately from the proposal of Cancani (1904), and other scales. Since the first group form a family of scales that are broadly compatible with one another, comparison issues are different from cases in which totally diverse scales are being compared. Some historical background is helpful here 
(see also Musson and Cecič 2002). Throughout this paper we use Arabic numerals for intensity, rather than the now rather antiquated Roman numerals, which are ill-adapted to computer files.

The history of how the Cancani family evolved is also the story of how the name of Rossi-Forel became forgotten, to be replaced to some extent by the name of Mercalli. Mercalli was actually the author of two intensity scales. The first of these (Mercalli 1883) is described by Davison (1921) as "merely an adaptation of the de Rossi scale". It has six degrees unlike the ten degrees of de Rossi, and is now more or less forgotten.

Mercalli's second scale, published in 1902, is a modification of the RF Scale (Mercalli 1902). The ten-degree structure is retained, but the descriptions of each degree are considerably amplified. For example, $5 \mathrm{RF}$ is defined:

Felt generally by everyone; disturbance of furniture and beds; ringing of some bells.

(In all these extracts the translations of Davison 1921, 1933, are followed. In this paper, we take examples mostly from lower intensity degrees as here the general points of comparison can be demonstrated more succinctly.) Compare Mercalli:

Rather strong, felt generally indoors, but by few outside, with waking of those asleep, with alarm of some persons, rattling of doors, ringing of bells, rather large oscillation of suspended objects, stopping of clocks.

Mercalli's fuller version found favour with users, and the scale was adopted as standard by the Central Office of Meteorology and Geodynamics in Rome (Davison 1921). A large number of incorrect remarks concerning this scale can be found in articles on the Internet, including common assertions that Mercalli invented the idea of intensity scales, and that the 1902 scale had twelve degrees. A modification was proposed by Cancani (1904) for dealing with very strong earthquakes, which consisted of adding two extra degrees at the top of the scale. 
Thus the first twelve-degree scale was born. Mercalli's 1902 scale already had titles for each degree, of which the top three (8-10) were "Ruinous - Disastrous Very Disastrous". The two new degrees (11-12) were labelled "Catastrophe" and "Enormous Catastrophe". This twelve-degree structure has come to dominate most of the scales in major use since. Ironically (in view of later developments), Cancani proposed that the new twelve degree scale be named the "Forel-Mercalli Scale" (thus cutting out de Rossi). In general, it saves confusion if scales are not named after people who are not their authors, and it is much better to follow Davison (1921) by referring to this innovation of 1904 as the Cancani Scale. Cancani's scale was never really usable as he proposed it, since his text consists only of the titles of each degree, i.e. one or two words per degree, plus a suggested peak ground acceleration equivalent. Consequently, the next development was the complete overhaul of the definitions of the degrees by Sieberg (1912). This involved very considerable expansion. Intensity 5 now read as follows:

Rather strong.

Even during the busiest hours of the day, the earthquake is felt by many persons in the open air. Indoors, the shaking of the whole building is generally noticed, the feeling being the same as when some heavy object (such as a sack or piece of furniture) falls in the house; or the observers move, together with chair, bed, etc., as in a ship on an agitated sea. Plants, the branches and weaker boughs of shrubs and trees sway visibly, as they do with a moderate wind. Freely hanging objects, such as curtains and lamps, but not heavy chandeliers, oscillate; small bells ring; the pendulums of clocks are stopped or swing more widely according as the direction of the shock is at right angles or parallel to the plane of oscillation; similarly, stopped pendulum clocks are set going; the striking spring of clocks sounds; electric lights fail to act when contact of the conducting wire is 
made; pictures rattle against the walls or are displaced; small quantities of liquid are spilt out of well-filled open vessels; ornaments, small standing frames fall and also objects leaning against the wall; even light furniture may be somewhat shifted from its place, rattling of furniture; doors and window-shutters open or shut; window panes crack. Sleepers as a rule are awakened. A few persons run into the open air.

Clearly this is changed far more from Mercalli (1902) than Mercalli is from RossiForel. Not only is the description greatly expanded in detail, a new class of information is added - effects on nature (plants sway visibly). And some details are actually changed. Mercalli has few people outside feeling the earthquake at intensity 5 , while Sieberg has many.

This scale is rightly referred to by Davison (1921) as the Sieberg Scale, and although the twelve-degree structure of later scales is derived from Cancani, (hence the title of this section of this paper) the content of most later scales is overwhelmingly influenced by Sieberg.

The new scale, clearly an advance on all previous scales, became in a later version (Sieberg 1923) referred to as the "Mercalli-Cancani Scale, formulated by Sieberg" - or more simply, the Mercalli-Cancani-Sieberg Scale, or MCS. The definition of the intensity degrees 1 to 6 of Sieberg (1912), are identical with those of Sieberg (1923). The innovations in Sieberg 1923, concentrate on the degrees 6 and 7 .

When the Sieberg (1923) scale was translated into English, with some changes, by Wood and Neumann (1931), while acknowledging the work of Sieberg in the text of their paper, in the title they picked out Mercalli and dropped Cancani and Sieberg, and the result was the Modified Mercalli Scale of 1931. Davison (1933) is more accurate in referring to this as the Wood-Neumann Scale. In the 
condensation of Sieberg's text, much helpful detail is lost, and Wood and Neumann's version is not an improvement. Where Sieberg (1923) has

... Plants, the branches and weaker boughs of shrubs and trees sway visibly, as they do with a moderate wind. Freely hanging objects, such as curtains and lamps, but not heavy chandeliers, oscillate ...

Wood and Neumann (1931) have

Hanging objects ... swing generally or considerably ... Trees , bushes, shaken slightly.

The former is more vivid and clearer.

Problems of nomenclature became more acute 25 years later, when the scale was completely overhauled by Richter (1958). Richter's changes were far reaching - in particular, he introduced a series of building classes based on typology, facilitating the assessment of intensity in cases where weak buildings are damaged but strong ones are not. This resulted again in a quite new scale, which, Richter realised, should be called the Richter Scale. However, by historical accident, the phrase "Richter Scale" was already in wide journalistic use for the local magnitude $\left(\mathrm{M}_{\mathrm{L}}\right)$ scale, and Richter correctly foresaw that having an intensity scale called after him would cause immense confusion. He therefore proposed that the scale be referred to as the Modified Mercalli Scale of 1956.

This proved a bad decision; it would have been better to call it something like the "California Scale". What happened was that thereafter intensity data sets appeared with the intensity given only as "Modified Mercalli" (or MM or MMI) with no indication of which scale was intended. To make matters even worse, subsequent authors followed the same course in producing further scales, and there is now a multiplicity of different scales calling themselves "Modified Mercalli" of one version or another, some of which are clearly not compatible with either the 1931 or 1956 scales (for instance, the version by Brazee 1978). As a 
result, in many papers it is hard to know exactly what is meant when "MMl" appears.

The latest version of "Modified Mercalli" appears to be that of Stover and Coffman (1993). One of the changes of this version is to downgrade damage to a few chimneys from intensity 7 to intensity 6 .

One also notes a carelessness in some authors, especially on the internet, in dropping the "Modified" and referring to the "Mercalli Intensity Scale" as if the 1902 version were still in use. This practice, justified by those who perpetrate it on the grounds of "ease of use", seems sometimes to stem from an ignorance that different scales exist.

In a parallel development, a new twelve-degree scale was created in 1962 by Medvedev, Sponheuer and Kárník, published as the MSK scale (Medvedev et al. 1964). This was broadly based on MCS, Wood and Neumann and Richter's work, and a previous scale by Medvedev, but arranged in a more systematic way. It was widely adopted in Europe.

In 1988 it was resolved by the European Seismological Commission to bring the MSK scale in line with modern building types and advances in macroseismology. The result was a new scale, called the European Macroseismic Scale (EMS) published in Grünthal (1998).

Scales in the non-Cancani group can be divided into three categories:

(i) Old scales predating 1904 e.g. Mercalli (1883).

(ii) Scales descended from the seven-degree scale of Omori (1900).

(iii) Later scales deliberately different from the Cancani family.

The second category comprises the different versions of the JMA Scale (Japanese Meteorological Agency). The most recent version of 1996 has increased the number of degrees from seven to nine, by dividing intensity 5 into 
"5 upper" and " 5 lower" and similarly for intensity 6 (JMA 1996). Present use of the JMA Scale is made by converting instrumental ground motion parameters into pseudo-intensity values (Yamazaki et al 1998); so one has no idea whether a quoted intensity value for a modern Japanese earthquake actually corresponded to the description of effects for that degree of the scale being observed or not. The replacement of the original JMA Scale with its instrumental version means that, to all intents and purposes, macroseismology is no longer practiced in Japan. Intensity is by definition a classification of observed effects. With earthquakes in Japan before 1996, the isoseismal 5 JMA marked the boundary of the area of observed damage to property. With later earthquakes, intensity 5 JMA indicates only a physical ground motion believed to be sufficient to cause damage to houses. Whether or not damage actually occurred is unknown. Scales in the third category are uncommon, but a fine example is found in Ambraseys and Melville (1982). This scale, intended for use for historical earthquakes in Iran, has five degrees. These are deliberately arranged so that intensity 1 is the most damaging and 5 the least; the inverse order to most other scales. This emphasises that the scale is intended to be unique to the matter in hand (historical Iranian sources) and not an alias or simplification for MSK or MMI.

\section{Conversion between intensity scales}

How can one convert between intensity scales? In the case of scalar parameters like magnitude, it is at least possible to regress one scale against another and produce a conversion formula that can then be applied to a given data set, to infer, say, Mw from Ms or vice versa. However, intensity is not a scalar; it is a classification according to the nature of effects. This is often expressed by the practice of writing intensities in Roman numerals to emphasise that these are integers and indivisible. (The practice of adding decimals in Arabic numerals after 
an intensity written in Roman numerals has, however, been seen - Klügel 2005 is an example.) The modern tendency is to write intensities with Arabic numerals as these are easier to handle in a computer file, but they are none the less integer classes. (There would be some justification in replacing the numbers in an intensity scale with letters: intensity A-L in a twelve degree scale. It should also be mentioned in passing that these strictures apply to intensity assessed from observations, and not necessarily to predicted intensity inferred from models.) Ideally, conversion should not be done at all; the correct and best procedure is to return to the original data and reassign values in the desired intensity scale (Ambraseys et al 1983, Günthal 1998 - see especially section 4.3). This is frequently very difficult or impossible, either because the original data no longer exist, or because of practical constraints of time and effort. In such cases some form of conversion is necessary, although it will add extra uncertainty to the final values.

One sometimes sees conversion diagrams in which different scales are represented as a series of blocks (one per degree of the scale) of different widths. One scale will be taken as a standard, and the width and placing of blocks in the other scales will vary according to the perceived relationship between the scales. Figure 1 illustrates the type of scheme (this one is imaginary, but real examples are found, for example, in Murphy and O’Brien 1977, Krinitzsky and Chang 1988, Reiter 1990 and Guidoboni and Ebel 2009). In it, one is led to infer that intensity 5 in scale A is slightly higher than intensity 5 in scale B, presumably because some diagnostics for intensity 5 in scale B appear in the description of intensity 4 in intensity scale A, and some diagnostics for intensity 6 in scale B appear under 5 in scale A. Figures of this type express something of the spread of correspondences between two scales in the eyes of an author, but do not provide direct practical guidance. When dealing with integer classes, there 
is no "slightly higher", and Figure 1 would not provide one with a clear means converting a data set.

A possible application of the approach would be in cases of this sort: imagine that for some earthquake the only information available for Derby was the following (imaginary) report:

In every place, the earthquake was generally felt only by those indoors; even in Derby few of those who were in the street at the time noticed anything

Now, consider two intensity scales $A$ and $B$, where the phrase "Felt by few persons outdoors" appears under intensity 4 in scale A, but under intensity 5 in scale B (leading to the sort of overlap shown in Figure 1). If one supposes that a seismologist would give an unqualified intensity assessment for Derby of 4 (scale A) or 5 (scale B) on the slender evidence above, then one can say that Figure 1 at least alerts one to the possibility that some values of 4 (scale A) are the equivalent of 5 (scale B). But one cannot know which, and one would hope anyway that one would not encounter firm, unqualified intensity assessments that rested on a single diagnostic in the way illustrated.

If a practitioner is faced with the task of giving a value to a data point in scale $A$ when all he has is a value in scale $B$, the question is whether he should assign one value or another. He has to make a working decision, and from Figure 1 one can read that intensity $5 \mathrm{~B}$ is broadly compatible with $5 \mathrm{~A}$, and therefore one would translate $5 \mathrm{~B}$ to $5 \mathrm{~A}$ if one had no other information. There may be a case where the two scales are so mismatched that (for instance) $5 \mathrm{~B}$ could be $4 \mathrm{~A}$ or 5 A with equal likelihood, and 4-5 A is the only answer. But slight overlaps are mostly of theoretical interest. A table of equivalence such as that in Willmore (1979) is more practical in giving direct numerical correspondences. The author of that table (N.V. Shebalin) leaves the reader in no doubt that if he wishes to 
convert some data from $\mathrm{MMI}$ to $\mathrm{MSK}$, where he has a value $5 \mathrm{MMI}$, his recommended course of action is to write 5 MSK.

Ostensibly, it appears that there are two possible ways to arrive at such a conversion table - an empirical way and a theoretical way. The empirical way would be to look at what intensities have been assigned to a body of data in scale A, compare with the intensities given to the same data using scale $B$, and examining the results. The theoretical way is to compare the actual wording of the scale degrees.

It might appear on the surface that the empirical approach is likely to be more robust, but in practice this is not the case, especially not where all the scales to be compared are within the Cancani family. The problems are as follows. Firstly, an experienced seismologist may develop a conception of the Platonic ideal for each intensity degree, and may then tend to assign intensities according to this ideal irrespective of what the scale actually says. Consider the following illustration. Suppose a description reads as follows:

In Derby, all over the town, windows and doors rattled, crockery and other light items were shaken and most people were awakened.

Now we consider two imaginary intensity scales in the Cancani family. In scale A, intensity 4 is defined as follows:

Many people indoors feel the earthquake. A few sleepers wake. Windows and doors rattle.

Scale B has the following definition:

The earthquake is felt generally indoors, and many or most are awakened. Crockery, windows, doors, etc are shaken perceptibly.

What is the intensity in Derby in scale A and B? Clearly there is a good match for intensity 4 in both scales. In the case of scale B one would assign intensity 4 
without hesitation. However, if one treats the definition in scale A literally, the intensity is actually higher than 4 , because at intensity 4 only a few are awakened whereas the report states that most were. So the literal-minded seismologist would assess an intensity of $4-5$ using scale $A$ and 4 using scale B. However, the less-literally minded seismologist would reason as follows, when using scale A: "This is obviously intensity 4 . I won't take into account the fact that scale A considers that only few should wake - if all the windows are rattling people will be woken by the noise. Therefore I will assign intensity 4; there is no evidence the intensity was any higher."

This is perfectly good reasoning, but it erodes any distinction between the two scales as regards values. In fact (and this is an important point that will be returned to later) the difference between scale $A$ and $B$ is not that intensity 4 is "slightly higher" in scale B, but in the fact that using scale B both imaginary seismologists arrive at the same value (4), whereas using scale A they arrive at different values (4-5 and 4). As a general rule, differences between seismologists in assessing intensity with the same scale are greater than differences assessed by the same seismologist using different scales, for scales within the Cancani family. This can often be seen in comparing evaluations of historical earthquakes where the same earthquake data have been assessed by different authors; no specific examples are cited here, as we do not wish to appear to highlight particular instances, but wherever the same data have been assigned intensities by different workers, differences will appear.

In fact, this follows directly from the subjective element in the assessment of intensity. To say that not everyone will make the same intensity assignment to the same data is a trivial observation. Thus, any empirical comparison of, say, MCS and EMS, could only be done on the basis of "MCS assigned by Dr A" compared to "EMS assigned by $\operatorname{Dr} B$ ". MCS assigned by $\operatorname{Dr} C$ might be systematically different, according to different working practices between $\mathrm{A}$ and 
C. For instance, Dr A might assume that any mention of damage guarantees an intensity of at least $7 \mathrm{MCS}$, while $\mathrm{Dr} \mathrm{C}$ may be prone to assuming that isolated reports of damage refer to buildings in such poor condition that they can be disregarded. This will lead to systematic differences in data sets even using the same scale. Therefore the attempt to compare scales empirically for general purposes, is problematic.

What if the same seismologist attempts to assign intensities using two difference scales, to explore the differences that way (e.g. Neilson et al 1984)? If one treats the wording of each degree very literally in order to wring out the maximum difference, one ends up assessing intensity in an artificial way, since most experienced seismologists would tend to interpret the scale in a freer way. If one uses the scales in a natural way, the seismologist's Platonic ideal for each intensity degree starts to have an effect, and any differences in the wording between two scales becomes eroded, as discussed above. One then tends to reach the conclusion that all scales in the Cancani family are largely equivalent. There are some exceptions to this where, even in scales within the same family, there are some obvious and inescapable differences. For example, some twelvedegree scales define intensity 1 as "the earthquake is not felt by anyone", and any positive observation, no matter how feeble, is at least intensity 2 (e.g. MSK). Others (e.g. Brazee 1978) consider that one or two observers feeling the earthquake on upper floors is intensity 1 . Thus an observation that is unambiguously intensity 1 on the Brazee scale is unambiguously 2 on the MSK scale.

When comparing scales that are not related, however, the anchoring effect that comes from familiarity with twelve-degree scales no longer has such an influence. If the fictitious description of effects in Derby given above is to be assessed in terms of the Mercalli (1883) scale, the seismologist must decide whether it fits better to intensity 2 : 
Moderate, with general shaking of fastenings, chandelier-prisms, etc., and ringing of some bells.

Or intensity 3:

Strong, more or less general ringing of bells, stopping of clocks, and oscillation of lamps.

And now having a feeling that the rattling of windows and doors "ought" to be intensity 4 (at least in MMI or MSK or EMS) cannot influence the result.

Empirical conversion really requires a situation is where it is desired to translate a particular data set from one scale to another, where the data set is based on a single set of working practices (usually meaning it was compiled by one seismologist over a period of time). One might perhaps find from observation (assuming the original data exist) that wherever this seismologist has assigned $7 \mathrm{MCS}$, the correct EMS assessment appears to be 6 EMS. In that case, and for this data set, one can conclude that $7 \mathrm{MCS}=6 \mathrm{EMS}$. But for other data sets compiled using different working practices this might not necessarily hold, and general empirical guidelines cannot be given.

Deriving a theoretical conversion by direct comparison of the wording of the scale could be done, as already suggested, by disassembling each intensity degree description into individual diagnostics, and then seeing where these fall with respect to a different scale. Thus if one found that for intensity 4 in scale A there were eight diagnostics, of which six were found repeated in scale B for intensity 4 and two under intensity 5 , this would lead to the sort of comparison found in Figure 1. It doesn't answer the question of how significant the discrepancy is in terms of actual use.

A more practical approach is to imagine that the description in scale $A$ is a report, and to attempt to assign an intensity to this report using scale B. To take the definition of intensity 3 in the first Mercalli scale as given above, and give the 
equivalence in EMS-98, one would imagine that a description of effects at some place matched the Mercalli definition exactly. This could read, for instance,

In Geneva, the shock was rather strong, and felt generally by those indoors, but by few outside. Many sleepers were woken, and some persons were alarmed by the rattling of doors and ringing of bells. There was a rather large oscillation of suspended objects, and some clocks stopped.

One would have little hesitation in assessing 5 EMS. This can then be repeated in the same way for all intensity degrees, including those involving damage (with some assumptions about likely vulnerability of buildings). In this way one can arrive at a table of equivalence for Mercalli and EMS as shown in Table 1. This process does involve some degree of subjectivity, but one can at least set out one's reasons for arriving at the decisions made.

\section{Conversion of the major scales to EMS-98}

Following in the manner of Table 1, in Table 2 the exercise is repeated for the major intensity scales encountered: Rossi-Forel, MCS, MM56, MSK and JMA (1996 version). In each case, each degree of the scale was rewritten as an imaginary news report and intensity assigned using EMS-98. These imaginary reports are not given here, but it is a trivial exercise to imagine each degree of a given scale rewritten in the style of a journalistic report (mostly a matter of changing the present tense to the past tense). This table is presented with some cautions:

1) In the first case, it must be recognised that its use should be thought of as a last resort, and that one should always attempt to reassign intensity values from the original data. At the very least, one should check conversions against original data if at all possible. 
2) These are theoretical relationships. In practice, any intensity data set is a conflation of the scale and the working practices used to apply it. The relationships in Table 2 are proposed guidelines, and should not be taken in a rigid and prescriptive way.

3) There might be a particular issue in the case of MCS. Experience seems to show that MCS intensity assignments are frequently higher than those in EMS for the same data, despite the fact that, assigning EMS intensities to the MCS scale descriptions themselves, generally leads to equality in our opinion. The difference may lie in the way in which the scale has been interpreted; this point needs to be investigated further.

4) There is no practical value, as already stated, in conversions that portray one scale as "slightly higher" than another. There is no "slightly higher" in an integer scale, so all conversions are given here in integers.

5) Conversions tend to break down at the top end of any scale. Most scales have a maximum degree which is defined, in some form of words, as "everything is destroyed". The meaning of this is ambiguous; it depends on what existed beforehand. If buildings are sufficiently poor, complete destruction may occur at an intensity well below the maximum conceivable earthquake shaking. In such cases, intensity scales saturate at what may be only around 9 EMS. This is a particular problem with the RF scale, which jumps from moderate damage at $9 \mathrm{RF}$ to total ruin at 10 RF. Nor does it help to add extra diagnostics not related to building damage, such as large-scale changes in landscape. These effects are often related to fault rupture or secondary ground effects, and generally don't help to define intensity degrees. Thus in Table 2, in most cases the top degree of older scales is undefined in terms of EMS (but may be presumed to be high). The issue is not critical, as these top degrees are seldom, if ever, used in practice. 
6) A literal reading of MSK and EMS-98 might suggest some differences, especially with regard to the occurrence of slight damage. In practice, experienced users of the MSK scale were not treating it literally, but making mental adjustments to the wording of the scale in order to arrive at intensity assessments that were robust and consistent with the overall pattern of the data (e.g. Burton et al 1984). One of the aims of the ESC Working Group for the revision of the MSK scale was to bring the wording of the scale into line with what seismologists were already doing as best practice (Grünthal 1989). Thus whatever differences there might apparently be in the wording of the scales, there should be no differences in MSK values and EMS values if the MSK values were correctly assigned. The greatest difference is likely to be that some MSK assessments that were given as split values due to uncertainty, e.g. 5-6 or 6-7, in many cases can now be resolved to a single degree. Most assignments of 5-6 MSK are likely to be 5 EMS, and 6-7 MSK is most likely to be 6 EMS.

7) The JMA Scale presents particular problems. As mentioned previously, since routine practice in Japan is to assign this from strong ground motion records, whether a JMA intensity value actually corresponds to any sort of observed effect is unknown. The descriptive interpretations still exist, but they are hard to interpret in terms of other scales because of significant discrepancies. According to the JMA scale, an intensity (3 JMA) where most people feel the earthquake and some are frightened (5 EMS) is the threshold at which objects begin to rattle slightly (4 EMS if not sometimes 3 EMS). The JMA Scale is unusual in having a degree zero (not felt). In most scales intensity 1 is not felt. 


\section{The evaluation of intensity scales}

In this section of the paper we consider comparisons between scales in the sense of deciding whether one scale is better for use than another. Superficial comparisons can be made between scales in the sense of whether one scale is longer than another, has more degrees in it, is intended for use in one country or another, and so on. But there are also features that one can find that make a scale actually more recommendable or less recommendable.

One can, for example, discard from consideration what Davison (1921) refers to as "personal scales" which are completely subjective, such as the very early Macfarlane scale (Milne 1842) which was used by Peter Macfarlane to compare the strengths of aftershocks of an earthquake on 23 October 1839. Rating the mainshock as 10 , Macfarlane considered that if he thought a shock was half as strong it rated 5 , and so on. Obviously this was a scale that no-one else could use.

The following are some criteria that need to be taken into consideration:

\section{Applicability}

A good scale should be easy to apply to many individual cases because the definitions are sufficiently copious to meet a range of different circumstances. If the definitions are very short, with few diagnostics, it may be hard in some cases to match a description of effects to the scale. Thus if one had a scale that contained only descriptions of effects indoors, one could not use it if all the data were from observers outdoors.

A specific problem is posed by the assessment of intensity for modern buildings that have earthquake-resistant design. For the same degree of shaking, these buildings should show less damage than older types of building. Thus, a scale that takes into account modern building types is likely to be more useful than a 
scale written to deal only with the building types that were prevalent fifty years ago.

However, the applicability issue does not translate simply into "more diagnostics equals a better scale", as increasing the length of each description causes one to run the risk of two pitfalls, as follows.

\section{Consistency}

The first pitfall is the issue of consistency. Are all the diagnostics for a given intensity really equivalent to the same degree of shaking? If a scale yokes together two diagnostics in the same degree that actually occur at different strengths of shaking, this will cause uncertainties in the application of the scale. This was a particular fixation of Davison's, as he makes very clear in his 1921 review. In the scale he devised for his own use, each intensity degree has one diagnostic only, so he could be sure that each degree was internally consistent (Davison 1900). Of course, this extreme solution meant that the scale was often impossible to apply.

A novel approach was pursued by Brazee (1978), who attempted to determine empirically from a large data set which diagnostic should be associated with which, using distance as discriminant. It is not really apparent that the results of this experiment are any better than other scales where the arrangement was made using judgement, and the scale has not been widely adopted.

\section{Discrimination}

This is an issue similar to that of consistency. Whereas the previous paragraphs dealt with the question that a diagnostic might be in the wrong place in the scale, the discrimination problem relates to cases where a diagnostic does not relate uniquely to any degree of the scale, and is thus is not useful in establishing the level of intensity. In some cases, a diagnostic may not be properly an expression 
of intensity at all. This is an important issue, often not correctly appreciated, which requires particular consideration. It is important to understand that intensity is an expression of earthquake shaking, and therefore all diagnostics should refer to phenomena that are the direct result of earthquake shaking. It is not just a collection of earthquake-related effects, and not all effects produced by an earthquake are suitable to be put into an intensity scale. For intensity to be useful as a concept, there must be an evident relationship between effect $A$ and intensity $Y$, such that the observation of $A$ occurring is evidence that the intensity was at least $Y$, and also that the observation that $A$ did not occur is evidence that the intensity was less than $Y$. If effect $A$ occurs at any intensity, it is not useful to have it in an intensity scale. Equally, if the absence of $A$ (even if the required sensor is present) is unrelated to intensity, then $A$ does not belong in an intensity scale.

As a very clear example, it is notable that very few intensity scales ever include remarks about human casualties, and with good reason (an exception is found in Principia 1982). Clearly, many other factors, like time of day, control the number of observed fatalities. One could, however, find a correlation between fatalities and intensity at least to the extent that many deaths usually indicate a high intensity. However, the absence of many deaths may mean only that people were out in the fields.

Direct fault rupture effects are a similar case. Absence of rupturing effects has to do with the characteristics of the fault (including its depth), and has nothing to do with shaking or intensity. Ground rupture, and effects contingent on it, thus have no place in an intensity scale. They may correlate with intensity (because typically the intensity will be high where the fault breaks) but they are not expressions of it. The fact that phenomena related to ground rupture were sometimes incorporated into earlier intensity scales, does not mean that this was ever good practice. A common example relates to the bending of railway lines, 
which first appears in Omori (1900) for intensity 6. Clearly, shaking of itself, no matter how strong, does not cause steel rails to bend. This is a secondary effect due to either fault displacement or ground failure.

Although effects on nature can be used, with great care, as reinforcing evidence of the level of intensity, it is not possible to rely on them exclusively. This has been pointed out several times (e.g. Vogt et al 1994, Musson et al 1995). The use of effects of nature has been encouraged by some authors on the grounds that otherwise, intensity values cannot be assigned at all in uninhabited areas (Dengler and McPherson 1993, Serva 1994). This is a problem one has to live with; neither can one assign intensities in the sea. It is better to leave mountainous areas as blanks on the map than to fill them with unreliable intensity values that may not actually show strength of shaking.

In conclusion, "applicability" is not always an advantage if the scale is written in such a way that real problems are concealed. The fact that a particular scale is written in such a way that using it, one can reach an intensity assignment for a place that might not be possible with a different scale, is not necessarily an advantage. The numbers may not be meaningful.

\section{Number of degrees}

The resolving power of an intensity scale is obviously related to the number of degrees in the scale. Montessus de Ballore was sceptical of intensity scales and remarked once that the only true scale would be one with two degrees - felt and not felt (Ballore 1916). One could obtain only very limited information using a scale at such an extreme position in the continuum between the rudimentary and the sophisticated. However, the extent to which one can resolve intensity degrees depends on two things: firstly, the quality of the data, and secondly, a certain irreducible chaos in even the most detailed macroseismic data set. 
If the quality of data is not good, and this is especially true of historical data sets, one cannot resolve intensities to the same fineness as may be defined in the scale. Thus, for a report, "In Verona many buildings were damaged," the intensity in a classic twelve-degree scale may be anywhere from 6 to 8 . Thus a six-degree scale that runs: not felt - weak - moderate - strong - damaging - destructive, may be as far as one can really discriminate (Musson 1991). On the other hand, with detailed contemporary data sets, such a scale would be found limiting, which is why early scales with few degrees, like Mercalli's first scale, were phased out in favour of scales of first ten and then twelve degrees.

However, even with a very detailed and copious data set, it will be found in practice that observations of earthquake shaking are somewhat irregular, due to the complexity and scattering of earthquake waves in the upper crust and soil column. As a result, even with many detailed reports from each settlement, the seismologist may find it hard to decide if the intensity is one degree or another.

As a result, it seems to be the case that twelve degrees is really the limit for a practical working scale. Any more, and the increased fineness of resolution could not actually be exploited using real data. This is a good reason for avoiding half intensity degrees, which would suppose that one could have a workable 23degree scale.

In fact, the top two intensities in a modern twelve-degree scale are used so infrequently that they can be effectively dropped, as is current USGS practice (Wald 2006, pers. comm.), and has been proposed in New Zealand also (Dowrick 1996).

Normally, a collection of questionnaires from a place (including internet-submitted responses) represents a very small and non-random sample of the total population. Inferences from such a sample as to the true intensity at the place may be questionable even at the resolution of integer intensity values; thus 
resolving values down to fractional or decimal degrees is probably a case of spurious accuracy. Intensities assigned from questionnaire data may not even be accurate to a resolution of one degree of a twelve degree scale. (However, hypothetical intensity values predicted from attenuation models can validly be expressed as decimals, as they don't reflect observational data.)

An intensity scale is a practical instrument with an end in view, and the number of degrees in any particular scale is likely to be a reflection of the purposes to which that scale is intended to be put. Thus having more or fewer degrees is not necessarily an advantage or disadvantage. It is no criticism of the scale in Ambraseys and Melville (1982) that it has only five degrees; that is a reflection of what can be discriminated using Persian historical records, and the scale does the task for which it was constructed.

\section{Regularity}

Determining correlations between intensity and simple measures of physical ground motion has proved difficult in the past, and prone to large scatter (e.g. Murphy and O'Brien 1977, Kaka and Atkinson 2004). Even though the concept of intensity is an integer classification, it is still to be hoped that intensity will behave more or less as if it were a physical parameter, and decay smoothly with distance. For this to be the case, the degrees of the scale need to be defined in such a way that the decrease in shaking with each lower value is regular. This should be clear in intensity datapoint distributions or isoseismal maps. If isoseismal maps drawn using a particular scale consistently showed a narrow gap between isoseismals 4 and 5, compared to the gap between 3 and 4 and between 5 and 6 , it would indicate that the scale was badly constructed (and similarly with intensity datapoint distributions).

Failure to find even spacing may reflect poor practice rather than poor scale design. A common observation is to see isoseismal maps in which the spacing of 
isoseismals 5 and 4 is very wide, and then the spacing suddenly drops below 4 so that isoseismals 4,3 and 2 are very tightly spaced. The most obvious explanation for this is poor practice in assigning intensity. If intensity values are assigned to individual questionnaires, instead of to communities on the basis of several questionnaires, then isolated returns that answer "yes" to "Did windows rattle?" will be rated 4 . This can result in a whole settlement being assigned intensity 4 on the basis of one observer with loose windows.

In general, the twelve-degree family of scales do a good job at preserving regular spacing when properly applied, which is one reason why the outline of the different degrees has been more or less stable for a hundred years. A common complaint that used to be addressed to the MSK scale was that there was a missing degree between 6 and 7 . This subject was investigated by the European Seismological Commission Working Group (WG) "Macroseismic Scales" (Grünthal 1993, 1998) in the course of revising the MSK scale to create EMS, with the conclusion that no new degree is necessary. Nor, for that matter, would such a new degree be advisable, as it would break up the existing regularity. The RF Scale is a good example of a scale with regularity problems, especially in the jump between 9 and 10 RF. This has been noted before, e.g. by Wood and Neumann (1931).

\section{Reliability}

If, as is argued above, all the Cancani-family scales are more or less equivalent in values, it might be wondered why any one should be preferable to any other. The key element in preferring one scale over another is the consistency with which the scale guides the user to the correct assignment for any place. As is well known, macroseismology contains an element of subjectivity, so that given the same data, two seismologists may assign different intensity values. Usually these differences are minor: one worker may assess 4-5 (4 or 5) where another is 
more certain that the value is 4 . All the same, anything that reduces subjectivity (or errors) is welcome. Thus, if two workers using scale A produce assessments of intensity that sometimes differ by up to two degrees, but when using scale B produce assessments that always agree, then, other things being equal, scale B is better.

To some extent, reliability is a function of other factors already discussed. So, for instance, a scale that has consistency problems is likely to cause users to come to different assignments, as each user has to find his way over the obstacle.

Another issue here is that the variability of earthquake effects in a given place means that a probabilistic approach, especially to damage, is advantageous. If a scale simply states that for a certain intensity, "chimneys are broken off at the roof line", users may react differently in cases where few or many, but not all chimneys are so affected. If a scale defines expected distributions of effects, rather than just the effects in isolation, it becomes easier to recognise the correct intensity assignment. This was a considerable advance in macroseismology, which came in really with the first version of the MSK scale in 1964.

One of the problems in the past that has led to inconsistent practices has been the fact that most scales have been published as lists of definitions without any corresponding guidance as to how the authors of the scale envisaged it being applied. A practice which has often been decried (rightly) in the past is that of assigning intensity on the basis of the highest effect reported. While this is undoubtedly wrong, one must have some sympathy for the observatory assistant who has been given a single sheet of paper with the Rossi-Forel Scale written on it, and told to start assigning intensities. For this reason, one of the first decisions taken by the ESC WG in revising the MSK scale was that the new scale should be accompanied by clear instructions as to exactly how the scale should be interpreted and applied. For this reason, EMS-98 is not simply a sheet of definitions, but includes guidelines intended to reduce misapplication. 
This discussion is predicated, of course, on traditional assessment of intensity from data by human judgement. This is bypassed when automatic algorithms are used to assess data using completely formulaic methods (e.g. Wald et al 1999, Musson 2006), but the traditional application of intensity scales will always be an issue in the assessment of historical data sets.

\section{Conclusions}

In an ideal world, one should not attempt to make conversions between different intensity scales, but rather re-assess data using the scale that one wishes to have the data expressed in. In practice, this may not always be possible, and conversion tables need to be applied. For practical purposes, the seismologist needs to know, if he has something assessed as 6 in scale $A$, what he should write down for the value in scale $B$.

Matters are complicated by the fact that, except where scales are radically different in organisation or number of degrees, differences in practice between seismologists tend to outweigh differences between scales. Thus, a value of 6 in scale A may have one value in scale B if it was originally assigned by one worker, and another value if originally assigned by someone else. Hence the advantage in going back to the original data.

To improve the usability of past data, we have included here a table intended to give guidance in converting data sets to EMS-98, but because of the way that any existing data set depends on working practices as well as the scale used, Table 2 should be used with care, and checks made if at all possible. Conversion in this manner should only be used where absolutely necessary; it would not be good practice to regard this table as a future panacea, such that old scales could continue to be used and then converted as required. This table is essentially the authors' assessments, in EMS-98, of imaginary press reports exactly expressing the descriptions of the various intensities in other scales. It is not, and cannot be, 
based on empirical analysis of data sets, because such an analysis would only be valid with respect to the agencies who produced those particular data sets.

Not all scales are equal; some are better than others. In particular, those that reduce disagreements between workers are better scales for everyday use. A good scale should guide everyone to making the correct judgement, and should minimise the degree of subjectivity. This means making sure that the definitions of each intensity degree are internally consistent in describing things that do go together with the same degree of shaking. While it is an advantage for a scale to deal with as many diagnostics as possible, it is not an advantage to include a diagnostic that is not reliably associated with any intensity degree. There is thus a trade-off between a scale that can be applied in very many cases to arrive at a number (but often the wrong one) and a scale which is less easy to apply in some cases (but gives more dependable answers).

A strong way to reduce disparate intensity assignments between workers is to have a scale that not only contains definitions of the various intensity degrees, but gives specific guidance as to how these definitions should be interpreted and used. The chief example here is the European Macroseismic Scale, which is the first macroseismic scale to include extensive guidelines as part of the scale itself.

\section{Acknowledgements}

The contribution of RMW Musson to this paper is included with the permission of the Director of the British Geological Survey NERC,.

\section{References}

Ad-hoc Panel 1981, Report on the Ad-hoc Panel meeting of experts on up-dating of the MSK-64 intensity scale, 10-14 March 1980. Gerlands Beiträge Geophysik, 90, 261-268. 
Ambraseys, N.N. and Melville, C.P. 1982, A history of Persian earthquakes. Cambridge University Press, Cambridge.

Ambraseys, N.N., Banda, E., Irving, J., Mallard, D., Melville, C.P., Morse, T., Muir Wood, R., Munoz, D., Serva, L., Shilston, D., Surinach, E. and Vogt, J. 1983, Notes on historical seismicity. Bulletin of the Seismological Society of America, 73, 1917-1920.

Ballore, F.d.M.d. 1916,. Earthquake intensity scales. Bulletin of the Seismological Society of America, 6, 227-231.

Brazee, R.J. 1978, Reevaluation of Modified Mercalli intensity scale for earthquakes using distance as determinant, Technical Memorandum. NOAA, NOAA.

Burton, P.W., Musson, R.M.W. \& Neilson, G. 1984, Studies of historical British earthquakes, BGS Global Seismology Report No 237, Edinburgh.

Cancani, A. 1904, Sur l'emploi d'une double echelle sismique des intensitès, empirique et absolue. Gerlands Beiträge Geophysik, 2: 281-283.

Davison, C. 1900, Scales of seismic intensity. Philosphical Magazine, 50, 44-53. Davison, C. 1921 , On scales of seismic intensity and on the construction of isoseismal lines. Bulletin of the Seismological Society of America, 11, 95-129. Davison, C. 1933, Scales of seismic intensity: Supplementary paper. Bulletin of the Seismological Society of America, 23, 158-166.

de Rossi, M.S. 1874, Bibliografia con annotazione. Bullettino del Vulcanismo Italiano, 1, 46-56.

de Rossi, M.S. 1883, Programma dell'osservatorio ed archivio centrale geodinamico presso il R. Comitato Geologico d'Italia. Bullettino del Vulcanismo Italiano, 10, 3-128. 
Dengler, L. and McPherson , R. 1993, The 17 August 1991 Honeydew earthquake, North Coast California: a case for revising the Modified Mercalli scale in sparsely populated areas. Bulletin of the Seismological Society of America, 83, 1081-1094.

Dowrick, D.J. 1996, The Modified Mercalli earthquake intensity scale - Revisions arising from recent studies of New Zealand earthquakes. Bulletin of the New Zealand Society for Earthquake Engineering, 29, 92-106.

Egen, P.N.C. 1828, Über das Erdbeben in den Rhein- und Niederlanden vom 23. Februar. 1828. Annalen der Physik und der physikalischen Chemie, 13, 153-163. Forel, F.A. 1881, Intensity scale. Archives des Sciences Physiques et Naturelle, 6, 465-466.

Grünthal , G., (ed.), 1989, Thoughts and proposals for the updating of the MSK intensity scale. Central Institute for the Physics of the Earth, Potsdam.

Grünthal , G., (ed.),1993, European Macroseismic Scale 1992 (up-dated MSKscale), Cahiers du Centre Europèen de Gèodynamique et de Seismologie. Conseil de l'Europe, Conseil de l'Europe.

Grünthal , G., (ed.), 1998, European Macroseismic Scale 1998, Cahiers du Centre Europèen de Gèodynamique et de Seismologie. Conseil de l'Europe, Conseil de l'Europe.

Guidoboni, E. and Ebel, J.E., 2009. Earthquakes and tsunamis in the past. Cambridge University Press, Cambridge. Japanese Meteorological Agency 1996, Explanation Table of JMA Seismic Intensity Scale, http://www.jma.go.jp/jma/kishou/know/shindo/explane.html. Kaka S-L, and Atkinson GM 2004, Relationships between instrumental groundmotion parameters and Modified Mercalli intensity in Eastern North America. Bulletin of the Seismological Society of America, 94, 1728-1736. 
Klügel, J.-U. 2005, Problems in the application of the SSHAC probability method for assessing earthquake hazards at Swiss nuclear power plants. Engineering Geology, 78, 285-307.

Krinitzsky, E.L. and Chang, F.K., 1988. Intensity-related earthquake ground motions, Bulletin of the Association of Engineering Geologists, 25, 425-435. Medvedev, S., Sponheuer, W. and Karník, V. 1964, Neue seismische Skala Intensity scale of earthquakes,. 7. Tagung der Europäischen Seismologischen Kommission vom 24.9. bis 30.9.1962. In: Jena, Veröff. Institut für Bodendynamik und Erdbebenforschung in Jena, Deutsche Akademie der Wissenschaften zu Berlin, 77, 69-76.

Mercalli, G. 1883, Vulcani e fenomeni vulcanici in Italia. In: Negri, G., Stoppani, A. and Mercalli, G. (eds.), Geologia d'Italia. Vallardi, pp 217-218.

Mercalli, G. 1902, Sulle modificazioni proposte alla scala sismica De RossiForel. Bollettino della Società Sismologica Italiana, 8, 184-191.

Milne, D. 1842, Report of the committee appointed at the meeting of the British Association held at Plymouth, in 1841, for registering shocks of earthquakes in Great Britain. Report of the British Association of the Advancement of Science, 92-98.

Murphy, J.R. and O'Brien, L.J. 1977, The correlation of peak ground acceleration amplitude with seismic intensity and other physical parameters. Bulletin of the Seismological Society of America, 67, 877-915.

Musson, R.M.W. 1991, The use of the MSK intensity scale in the study of British earthquakes. 3rd International Symposium on Historical Earthquakes in Europe, Liblice, 5-12.

Musson R.M.W., 2006, Automatic assessment of EMS-98 intensities. British Geological Survey, Technical Report IR/06/048. 
Musson, R.M.W., Grünthal, G. and Stucchi, M. 1995, Comment on "The 17 August 1991 Honeydew Earthquake: a Case for Revising the Modified Mercalli Scale in Sparsely Populated Areas" by Dengler and McPherson. Bulletin of the Seismological Society of America, 85, 1266-1267.

Musson, R. M. W., and I. Cecic 2002, Macroseismology, In: Lee, W. H. K., Kanamori, H., Jennings, P. C. \& Kisslinger, C. (eds.) International Handbook of Earthquake and Engineering Seismology, 807-822, Academic Press, San Diego. Neilson, G., Musson, R.M.W. and Burton, P.W. 1984, The "London" earthquake of 1580 April 6. Engineering Geology, 20, 113-142.

Omori, F. 1900, Intensity scale. Earthquake Investigation Committee publication in foreign languages, 4, 137-141.

Reiter, L., 1990. Earthquake hazard analysis. Columbia Univeristy Press, New York.

Richter, C.F. 1958, Elementary Seismology. W. H. Freeman, San Francisco. Serva, L. 1994, Ground effects in intensity scales. Terra Nova, 6, 414-416.

Sieberg, A. 1912, Über die makroseismische Bestimmung der Erdbebenstärke. Gerlands Beiträge Geophysik, 11, 227-239.

Sieberg, A. 1923, Geologische, physikalische und angewandte Erdbebenkunde, G. Fischer, Jena.

Stover, C. W., and J. L. Coffman 1993, Seismicity of the United States, 15681989 (Revised), United States Government Printing Office, Washington.

Vogt, J., Musson, R.M.W. and Stucchi, M. 1994, Seismological and hydrological criteria for the new European Macroseismic Scale (MSK-92). Natural Hazards, 10, 1-6. 
Wald, D.J., Quitoriano, V., Dengler, L.A. and Dewey, J.W. 1999, Utilization of the Internet for rapid community intensity maps. Seismological Research Letters, 70, 680-697.

Willmore, P.L. (ed.) 1979, Manual of Seismological Observatory Practice. World Data Centre A for Solid Earth Geophysics, U.S. Department of Commerce, NOAA, EDIS, World Data Centre A for Solid Earth Geophysics, U.S. Department of Commerce, NOAA, EDIS, 165.

Wood, H.O. and Neumann, F. 1931, Modified Mercalli intensity scale of 1931. Bulletin of the Seismological Society of America, 21, 277-283.

Yamazaki F., Noda S. and Meguro K. 1998, Developments of early earthquake damage assessment systems in Japan. 7th International Conference on Structural Safety and Reliability, 1573-1580 


\section{Tables}

\begin{tabular}{cc}
\hline Mercalli (1883) & EMS-98 \\
\hline 1 & 2 or 3 \\
2 & 4 \\
3 & 5 \\
4 & 6 or 7 \\
5 & 8 or 9 \\
6 & 10 or 11 \\
\hline
\end{tabular}

Table 1

Conversion from Mercalli (1883) to EMS-98

\begin{tabular}{cccccccccc}
\hline RF EMS-98 & MCS EMS-98 & MMI 56 EMS-98 & MSK EMS-98 & JMA-96 EMS-98 \\
\hline & & & & & & & & & \\
1 & 1 & 1 & 1 & 1 & 1 & 1 & 1 & 1 & 2 or 3 \\
2 & 2 & 2 & 2 & 2 & 2 & 2 & 2 & 2 & 4 \\
3 & 3 & 3 & 3 & 3 & 3 & 3 & 3 & 3 & 4 or 5 \\
4 & 4 & 4 & 4 & 4 & 4 & 4 & 4 & 4 & 5 \\
5 & 5 & 5 & 5 & 5 & 5 & 5 & 5 & $5 \mathrm{~L}$ & 6 \\
6 & 5 & 6 & 6 & 6 & 6 & 6 & 6 & $5 \mathrm{U}$ & 7 \\
7 & 6 & 7 & 7 & 7 & 7 & 7 & 7 & $6 \mathrm{~L}$ & 8 \\
8 & 7 or 8 & 8 & 8 & 8 & 8 & 8 & 8 & $6 \mathrm{U}$ & 9 or 10 \\
9 & 9 & 9 & 9 & 9 & 9 & 9 & 9 & 7 & 11 \\
10 & $*$ & 10 & 10 & 10 & 10 & 10 & 10 & & \\
& & 11 & 11 & 11 & $*$ & 11 & 11 & & \\
& & 12 & $*$ & 12 & $*$ & 12 & $*$ & & \\
\hline
\end{tabular}

Table 2

Non-prescriptive guidelines to conversion from five major scales to EMS-98. * = this intensity is defined in such a way that it relates to phenomena that do not represent strength of shaking e.g. those due to surface faulting, or reaches a 
saturation point in the scale, where total damage refers to total damage to buildings without antiseismic design. 


\section{Figure Captions}

Figure 1

Overlapping block comparison of two scales (partial); this is a fictitious example to demonstrate the general principle 
Figures

Scale Scale

A B

\begin{tabular}{|l|l|}
\hline 6 & 6 \\
\hline 5 & 5 \\
\hline 4 & 4 \\
\hline 3 & 3 \\
\hline 2 & 2 \\
\hline
\end{tabular}

Figure 1 